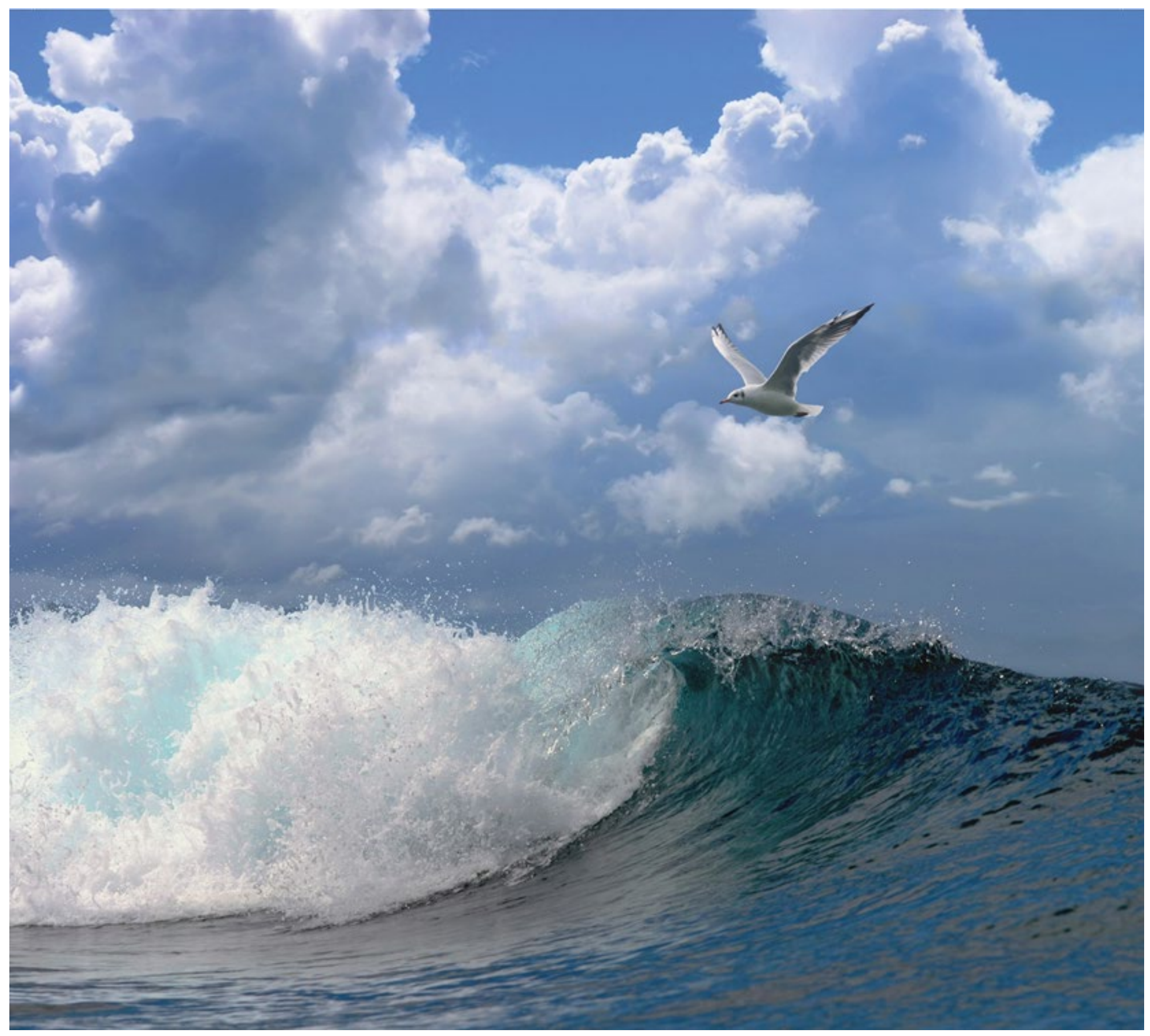

\title{
Baited camera to identify macro-fauna species and their abundance in close proximity to seaweed farms
}

Technical report 


\section{Baited camera to identify macro-fauna species and their abundance in close proximity to seaweed farms}

Technical report

Author(s): $\quad$ Alexander Lubsch, edited by Romy Lansbergen

This research project was carried out by Wageningen Marine Research and subsidized by the ministry of Agriculture, Nature and Food Quality for the purposes of Knowledge base research project

'Circular and Climate Neutral society (project no. KB-34-007-004).

Wageningen Marine Research

Yerseke, January 2021

CONFIDENTIAL no

Wageningen Marine Research report C111/20 
Keywords: video-techniques, biodiversity, seaweed farming, shellfish aquaculture.

Client: $\quad$ Ministerie van LNV

Postbus 20401

2500 EK Den Haag

This report can be downloaded for free from https://doi.org/10.18174/536727

Wageningen Marine Research provides no printed copies of reports

Wageningen Marine Research is ISO 9001:2015 certified.

\section{(C) Wageningen Marine Research}

Wageningen Marine Research, an institute Wageningen Marine Research accepts no liability for consequential damage, nor within the legal entity Stichting for damage resulting from applications of the results of work or other data Wageningen Research (a foundation under obtained from Wageningen Marine Research. Client indemnifies Wageningen Dutch private law) represented by Marine Research from claims of third parties in connection with this application. Dr.ir. J.T. Dijkman, Managing director All rights reserved. No part of this publication may be reproduced and / or published, photocopied or used in any other way without the written permission of the publisher or author.

KvK nr. 09098104,

WMR BTW nr. NL 8113.83.696.B16.

Code BIC/SWIFT address: RABONL2U

IBAN code: NL 73 RABO 0373599285 


\section{Contents}

$\begin{array}{lr}\text { Summary } & 4\end{array}$

$1 \quad$ Introduction $\quad 5$

$\begin{array}{llr}2 & \text { Objective } & 8\end{array}$

$3 \quad$ Materials and Methods $\quad 9$

$4 \quad$ Results preliminary test on baited camera settings $\quad 11$

4.1 Test site 11

4.2 Preliminary test results $\quad 11$

4.3 Video monitoring at seaweed site $\quad 12$

4.3.1 Study site 12

4.3.2 Experimental design 13

4.3.3 Analysis of video footage 13

$5 \quad$ Results $\quad 14$

5.1 Early afternoon $\quad 14$

$\begin{array}{ll}5.2 & \text { Early evening } \\ 5.3 & 16\end{array}$

$\begin{array}{lll}5.3 & \text { Early afternoon vs. early evening } & 16\end{array}$

5.4 November 2018 vs July $2020 \quad 17$

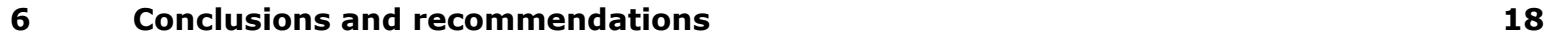

6.1 General conclusions $\quad 18$

6.2 Infrared cam vs. action cam 19

$\begin{array}{lll}6.3 & \text { Recommendations } & 19\end{array}$

$\begin{array}{llr}7 & \text { Quality Assurance } & 20\end{array}$

$8 \quad$ Acknowledgement $\quad 21$

$\begin{array}{lr}\text { References } & \mathbf{2 2}\end{array}$

$\begin{array}{lr}\text { Justification } & 23\end{array}$ 


\section{Summary}

The ambitions for large scale cultivation of seaweed has been gaining in popularity, good ecological monitoring of these newly introduced habitats is necessary to assess the impact of these new habitats. Naturally occurring seaweed habitats provide a nursery for juvenile fish and have a high biodiversity. It is therefore expected that seaweed cultivation site will increase the local biodiversity. To be able to monitor this baited camera systems were selected as a potential solution for mobile species. Monitoring with a camera is the least intrusive method of monitoring and provided the additional advantage of video footage or pictures, which can be used in presentation of public outreach campaigns. In this study an infra-red camera was tested and compared with an action camera, using a baited camera setup. The setup proved to attract both omnivorous as carnivorous fish. However the time of day in which the monitoring was conducted proved important, in early afternoon recordings there is more activity recorded than in the early evening. Also a difference in season was found, as expected November showed different types of fish than July. Additionally the ability to taxonomically identify the fish was studied by comparing the footage of the infra-red camera with footage of the action cams. The footage of the infra-red camera was more difficult to identify fish on than the action camera's. Additionally having multiple camera's aimed at the bait from different angles provides better identification options. Identification proved to result in more difficulties, due to the nursery function of seaweed habitat most fish found where in their juvenile stage. It is expected that having a seaweed cultivation system will attract more biodiversity over time, a long scale monitoring over different seasons is therefore advised. To provide a wider range of identification options, automated visual recognition should be considered for future development. 


\section{Introduction}

Baited (remote) underwater video cameras are a common fish-surveying tool around the world. These baited underwater video cameras use bait inside a mesh bag, which is attached to an arm in front of the camera lens to attract fish in the vicinity, recording the species attracted to the bait or swimming past the lens. The recorded footage is analysed in the laboratory, where species can be identified by specialists and their relative abundance documented. Future developments will make this possible in real-time settings (remote monitoring).

Biodiversity is an important measure for the health of an ecosystem and often regarded as a framework for environmental policy. Seaweed and shellfish farming may enhance local biodiversity at a production site as the growing seaweed thalli provide a versatile habitat and nursery ground for juvenile fish. On the other hand, seaweed or shellfish farms can also facilitate the introduction of exotic invasive species. As these introduced species may compete for resources with indigenous species, this could result in a local decrease of biodiversity. It is necessary to quantify the biodiversity in seaweed and shellfish farms in order to understand how they affect marine ecosystems. However, since traditional methods to measure biodiversity are often complicated and labour-intensive, innovative and novel techniques are needed to approach this question.

Video monitoring in marine environments provide excellent opportunities to conduct research in areas difficult for divers to access and offers many advantages over traditional diver-based monitoring, such as observations in sensitive areas or dangerous places, as this technique is harmless to fish and habitat and diver. The restrictions on safety procedures for future multi-use aquaculture settings add an additional complexity for application of monitoring. In addition a record of observations for future reference and quality assurance can be created by using video monitoring techniques. Providing the additional advantage of an easy exchange of visual information between researchers, stakeholders, and the public.

This simple, but effective marine life monitoring technique requires inexpensive action cameras installed to a simple and robust underwater housing, a steel frame that also holds a bait arm (Figure 1). Cameras held in different positions on the steel frame pointing towards the bait allow for easy identification of species, as well as allow precise length and biomass analysis of paired images. Lights can be added for low light and night surveys. Similarly, infrared lights can be added to record species that normally avoid bright visual light. The steel frame is attached to a rope and floating surface marker that allows for retrieval. 


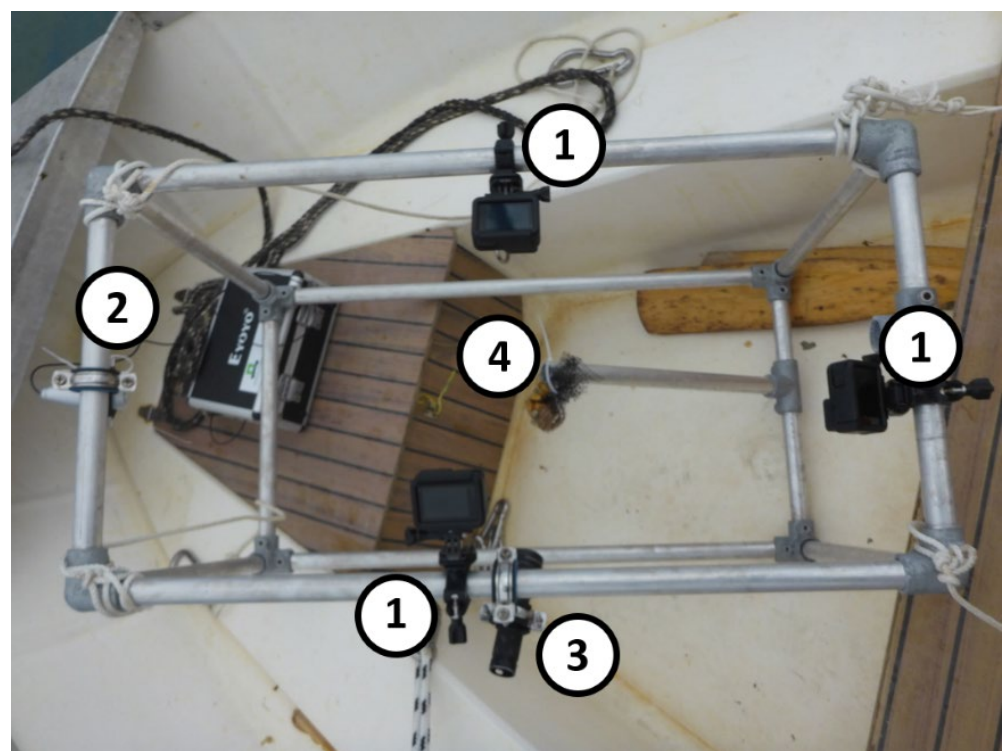

Figure 1 Steel frame (approximate length: $80 \mathrm{~cm}$, width: $47 \mathrm{~cm}$, height: $40 \mathrm{~cm}$, weight: $12 \mathrm{~kg}$ ) with a bait arm extending $35 \mathrm{~cm}$ towards the centre and a mesh bag attached to its tip (4), which is targeted by 3 action cameras (1), infrared camera (2), and light source (3).

For fish, times of dawn and dusk are of great activity. As the sun rises during dawn, diurnal fish leave deeper waters, where they often rest, to begin their feeding activities. Many seaweed species represent a food source for primary consumers (McClelland \& Valiela 1998) and at the same time offer protection from predators and/or serve as a nursery (Lalli \& Parson 1997). Nocturnal fish behave the opposite way and return from their hunting grounds to deeper waters to wait out the upcoming day. In addition dawn triggers spawning in many fish species, potentially lowering the risk of the eggs being eaten by other species. At dusk the processes observable during dawn are reversed and diurnal fish move to deeper waters or into dense vegetation for protection, while nocturnal fishes emerge. Therefore, it is advisable to focus video monitoring on time windows during dawn and dusk, when greatest fish activity during the day can be expected.

Furthermore, most fishes exhibit a seasonal cycle in their reproduction. Different fishes spawn during specified periods of the year, which coincides with several environmental factors of which photoperiod and temperature, i.e. increased day length, are considered to be important factors controlling spawning activities (Hazard \& Eddy 1951). The spawning activity, respectively the length of breeding period is extremely variable, and some species spawn only once, others twice, and some species may spawn several times during a year. To understanding the contribution of reproduction of fish in seaweed cultures monitoring techniques to quantify mobile biodiversity abundance are needed.

Fish assemblages in the central and northern North Sea are very different to those assemblages further south, including Dutch waters (Teal 2011). The fish assemblages correspond with changes in water depths and temperature (Callaway et al. 2002). The southern North Sea is generally shallower $(<50$ $\mathrm{m}$ ) than the northern parts. Correspondingly, dominant fish species are those that are characteristic of inshore waters, e.g. benthic flat fish, as Solea vulgaris (sole), Limanda limanda (dab), and Pleuronectes platessa (plaice), as well as pelagic fish, like Merlangius merlangus (whiting) and also other species from the order Gadiformes (Callaway et al. 2002). While benthic fishes are unlikely to enter an offshore seaweed cultivation site close to surface waters, pelagic fish and especially their juvenile, e.g. young haring, that prey on smaller organisms, i.e. mesograzer (e.g. isopods, amphipods, gastropods), could very well be attracted.

A recent study in the Eastern Scheldt, an inshore delta system in the south of the Netherlands, has shown a great abundance of the amphipod Caprella spec. on introduced seaweed cultivation ropes, but an overall low diversity of meso-fauna (Bernard \& Tonk 2019). Nevertheless, these amphipods may be part of the diet of many carnivore and omnivore fish. An overview of fish species in the Eastern Scheldt per season was elaborated by Gmelig Meyling et al. (2013), based on a data collection by means of diver surveys (Table 1 ). 
Table 1 Overview of fish species in the Eastern Scheldt per season (retrieved from Gmelig Meyling et al. 2013; Stichting Anemoon, Netherlands). 'Feed' indicates whether species are carnivorous (car), herbivorous (her) or omnivorous (omn).

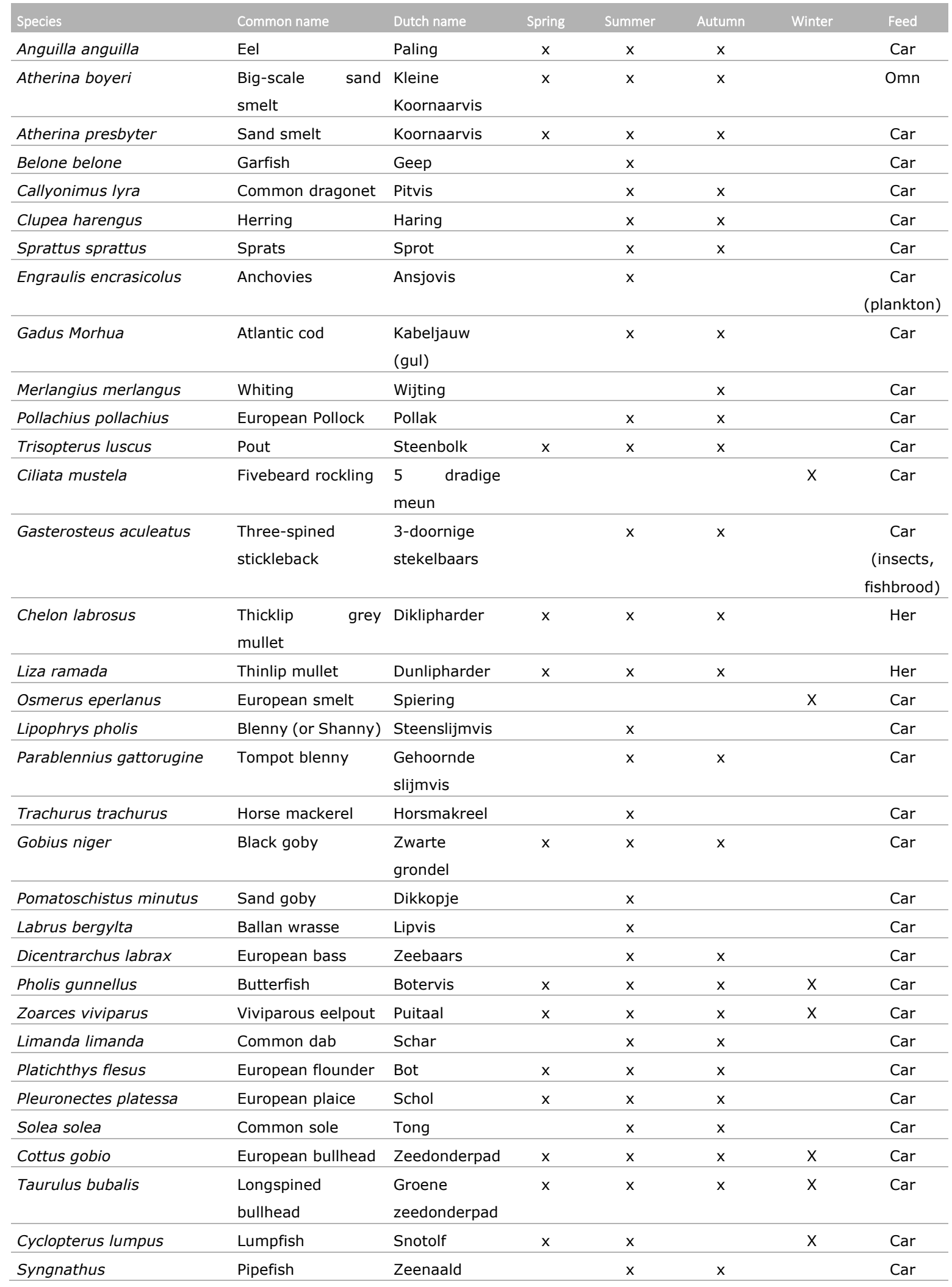




\section{Objective}

In this study, we investigated video techniques (visual, infra-red) in respect to their applicability to identify and quantify mobile fauna in close proximity to a seaweed test farm, following the studies on remote video techniques from Tonk et al. (2018). In addition, this report focusses on the temporary (daily) appearances of mobile fauna. Diversity and abundances of species in a newly introduced seaweed cultivation site may shift over time, as well as frequency of visits by fish (and mammals, such as seals) may increase over season and year in accordance with acquaintance of the (location of the) site. Thus continuous monitoring over several seasons and years is recommended.

Depending on the size of the cultivation, more than one baited framework with cameras can be installed to monitor huge areas at a time. Typically visual sight in the North Sea and coupled delta systems is restricted to approximately one meter or less, depending on depth and turbidity. Consequently, this video technique can only be applied to determine species of macro-fauna that are close to the camera's lens, while meso-fauna can barely be detected, nor taxonomically identified from camera footage. Mesofauna must be examined in a different approach, for example retrieving sections of cultivation rope and attached biomass for identification in the laboratory by binocular and/or microscope.

It is important to understand drivers, such as the modification of an habitat as represented by the introduction of large scale seaweed cultivation operations. In order to be able to make projections on how these may affect the fish community in the future. As well as the effect of the 'loss' of cultivated seaweed biomass due to grazing and (temporary) occupation for nursery. To address these ecologically important research questions, WUR has launched a video monitoring project. 


\section{Materials and Methods}

In preliminary tests, the visual sight of the action cameras (GoPro ${ }^{\mathrm{TM}}$ Hero 7) and infra-red camera (Eyoyo $^{\mathrm{TM}}$ fish-finder) are assessed, as well as the addition of a light source (optional) and their position and angle towards the bait is configured along the steel frame for best view. The bait is placed in a plastic mesh (or onion bag), stocked with a mixture of rag worms, fish remainders, shellfish flesh, bread, and corn to attract carnivore, herbivore, and omnivore fish. To test the functionality of the apparatus in a marine environment, for instance, a small harbour can serve as an easy accessible location, offering sufficient depth for measurements under the water surface and under poor natural light conditions, either by the depth itself or shading of incoming sunlight by parked boats or landing stages, similar to the blocking of sunlight inside a dense seaweed cultivation site. In the harbour, artificial light sources can be tested and adjusted with ease.

In correspondence to seaweed cultivation, seasons and fish migration, as well as fish feeding behaviour and reproduction cycles. Video monitoring should focus on different daytimes, like dawn, noon, and dusk during spring- and summer time. Previous studies on baited cameras in the Easter Scheldt showed the appearance of different fish, like big-scale sand smelt (Atherina boyeri) and horse mackerel (Trachurus trachurus), after 20 seconds, respectively 31 seconds, after deployment and fish activity peaked after 5 to 6 minutes (Tonk et al. 2019).

Recordings at noon may serve as reference data. Battery power and data storage capacity of the cameras (32 GB) are limited, thus constrict the duration of video monitoring.

Analysis of the footage, respectively identification of recorded species is done in the laboratory by specialists. Footage and photographs of the species can serve for future reference and quality assurance, as well as can help to communicate and exchange information between researcher, stakeholder, and the public. A summary of the experimental set up is represented in Table 2. 
Table 2 Summary of preliminary tests, including test parameters and their function in video monitoring techniques to identify marine macro-fauna species.

\begin{tabular}{|c|c|c|}
\hline Test & Parameter & Function \\
\hline Visual sight I (cameras) & $\begin{array}{l}\text { - action camera (4K) } \\
\text { - infra-red camera }(800 \times 480) \\
\text { - position and angle }\end{array}$ & - recording of species \\
\hline Visual sight II (lights) & $\begin{array}{l}\text { - visual light (PAR) } \\
\text { - infra-red } \\
\text { - position and angle }\end{array}$ & - improvement of visual sight \\
\hline Bait & $\begin{array}{l}\text { mesh or onion bag with: } \\
\text { - rag worms } \\
\text { - bread } \\
\text { - corn } \\
\text { - fish remainders } \\
\text { - ensis (shellfish) flesh } \\
\text { or combination of the above }\end{array}$ & $\begin{array}{l}\text { - a mixture to attract } \\
\text { carnivores, herbivores and } \\
\text { omnivores in the vicinity }\end{array}$ \\
\hline Season & $\begin{array}{l}\text { - spring } \\
\text { - summer } \\
\text { 2-3 days per season }\end{array}$ & $\begin{array}{l}\text { - Harvest of winter seaweed } \\
\text { cultivation, start of summer } \\
\text { cultivation. } \\
\text { - high food web activity } \\
\text { - empirical season coverage }\end{array}$ \\
\hline Daytime & $\begin{array}{l}\text { - morning } \\
\text { - afternoon } \\
\text { - evening } \\
\text { for } 30 \text { - } 60 \mathrm{~min}\end{array}$ & $\begin{array}{l}\text { - fish behaviour in daily feeding } \\
\text { and migration } \\
\text { - empirical daytime coverage }\end{array}$ \\
\hline Data analysis & $\begin{array}{l}\text { - pictures of relevant species } \\
\text { - video sequences }\end{array}$ & $\begin{array}{l}\text { - identification of species } \\
\text { - easy exchange of data } \\
\text { - future reference (also for } \\
\text { automated monitoring) } \\
\text { - public relations (transparency) }\end{array}$ \\
\hline Test location & $\begin{array}{l}\text { Easily accessible location: } \\
\text { - coastal seaweed site } \\
\text { - fish farm } \\
\text { - small harbour } \\
\text { - seaweed farm (optional) }\end{array}$ & $\begin{array}{l}\text { - test and adjustment of all } \\
\text { applications }\end{array}$ \\
\hline
\end{tabular}




\section{Results preliminary test on baited camera settings}

\subsection{Test site}

Settings of the cameras, as well as adjustment of cameras angles and lights were tested in a public part in the harbour in Yerseke (Bakenweg, 4675 RB) (Figure 2 Google $^{\mathrm{TM}}$ satellite image of test location at the Yerseke harbour (N 5150'0.38", E 405'36.37"). Figure 2).

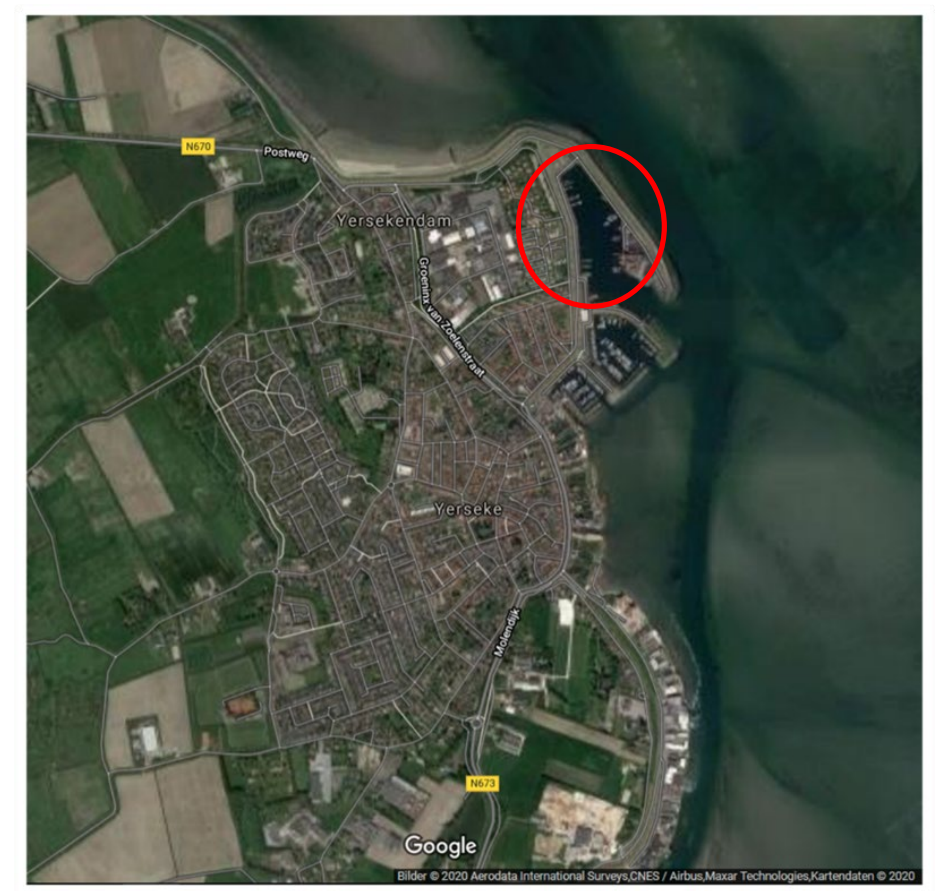

Figure 2 Google TM $^{\mathrm{TM}}$ sallite image of test location at the Yerseke harbour ( $N$

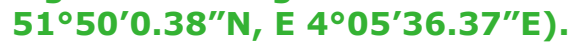

\subsection{Preliminary test results}

Visual appearance of objects in the video footage was well inside the boundaries of the steel frame in terms of focus and general visibility. Outside its boundaries ( $>1 \mathrm{~m}$ ) on the other hand, general visibility was drastically reduced due to turbidity and low light. An increase in light intensities from moderate to high level (3-way light source: dim; moderate; high) caused extremely bright reflections of plenty suspended particles (high turbidity) close to the light source and camera lenses. Thus, this did not increase general visibility and made it more difficult to identify species at all (compare Figure 3). Good vision was reached at a moderate light level with the light source pointing at the bait net in a $45^{\circ}$ angle from a top bar of the steel frame. Similarly, all cameras were attached on each site of the steel frame on the top bar, pointing downwards in a $45^{\circ}-60^{\circ}$ angle, focussing on the bait in the centre of the structure.

The installation of an infra-red camera fish-finder (Eyoyo ${ }^{\circledR}$, Underwater Fishing Camera, HD 1000TVL) connected to a 9" TFT monitor (50 fps; $800 \times 480$, AVI) by cable (30m) offering live feat made it possible to control the correct placement and attachment of the bait. After submerging the heavy steel frame to its operating depth at 1.5 meters, this set-up allows to survey and coordinate the position of structure (Figure 4). A disadvantage of this installation is the connection by cable to a screen and energy supply (DC 12.6V), as the site cannot be left to avoid disturbances and potential noise caused on a boat, which might fear off mobile fauna. 


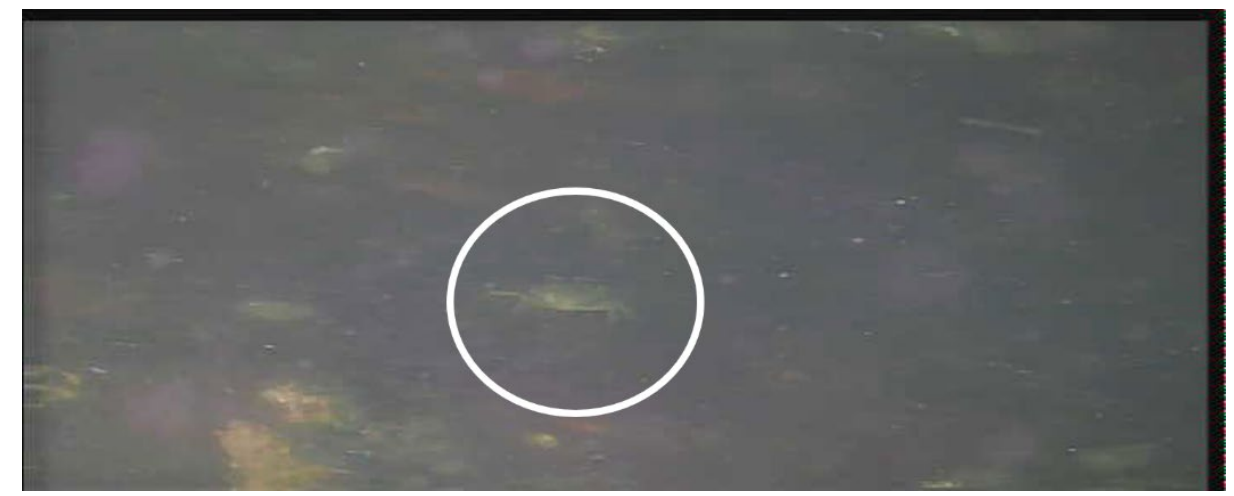

Figure 3 Video snap-shot of a crab (unidentified) on the retaining wall at Yerseke harbour taken with Eyoyo ${ }^{\mathrm{TM}}$ fish-finder infrared camera.

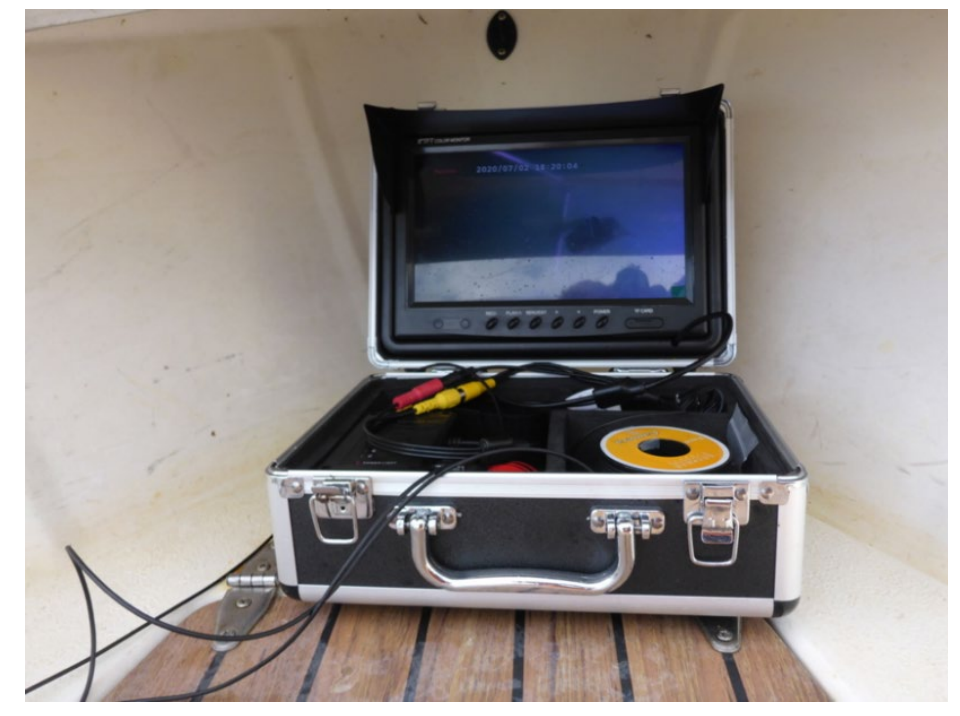

Figure 4 Еуоуо $^{\mathrm{TM}}$ fish finder set up (TFT monitor) for live feat allows to control orientation and position of the baited system, as well as enables a direct observation.

\subsection{Video monitoring at seaweed site}

\subsubsection{Study site}

Video monitoring took place in the Schelphoek in the Eastern Scheldt, at a seaweed test farm (Figure 5 ), operated by Seaweed Harvest Holland B.V., on the $2^{\text {nd }}$ of July 2020 around early afternoon ( 14 h00 - 14h45) and in the evening (17h30 - 18h30).

The test farm consists of 16 doubled-lined rows of horizontally arranged cultivation ropes and overall dimensions of approximately $200 \mathrm{~m} \times 50 \mathrm{~m}$ (compare Figure 5B). The cultivated seaweed species prevailing on the cultivation ropes was the perennial brown seaweeds Saccharina latissima (Figure 6). 


\subsubsection{Experimental design}

The baited cameras were deployed at the south-east side of the farm between the very first 2 rows of the seaweed cultivation ropes at a depth of approximately $1.5 \mathrm{~m}$. A mixture of defrosted crab and defrosted mussel meat were used as a bait for both recordings, in the early afternoon (14h00 - 14h50) and in the evening $(17 \mathrm{~h} 35-18 \mathrm{~h} 25)$. All recordings were conducted at the same location with the same camera settings. Due to the experimental design, this study focussed on pelagic species and does not include assessment of benthic species and composition.
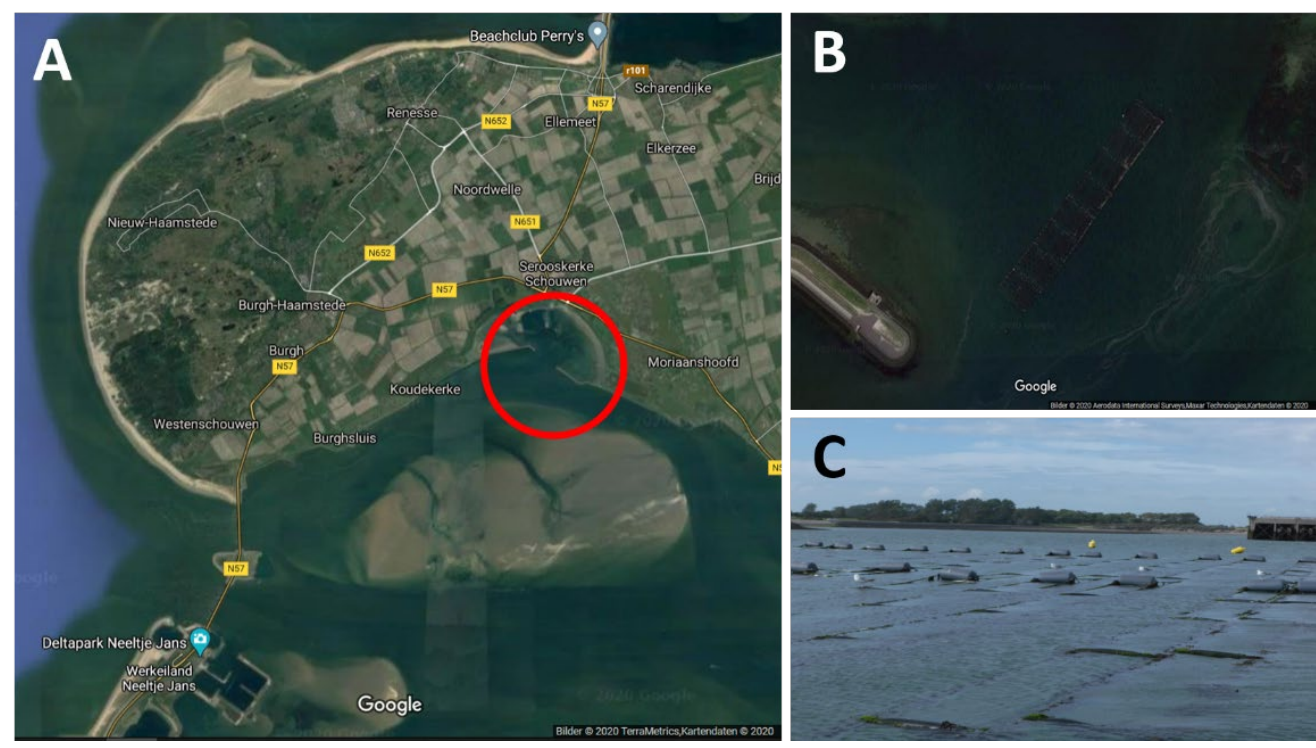

Figure 5 ( $\mathrm{A}$ ) Google ${ }^{\mathrm{TM}}$ satellite image of the study site in the Eastern Scheldt (Schelphoek marked with red circle) (B) zoomed-in satellite image of the seaweed cultivation installation, and (C) photograph of the study site.

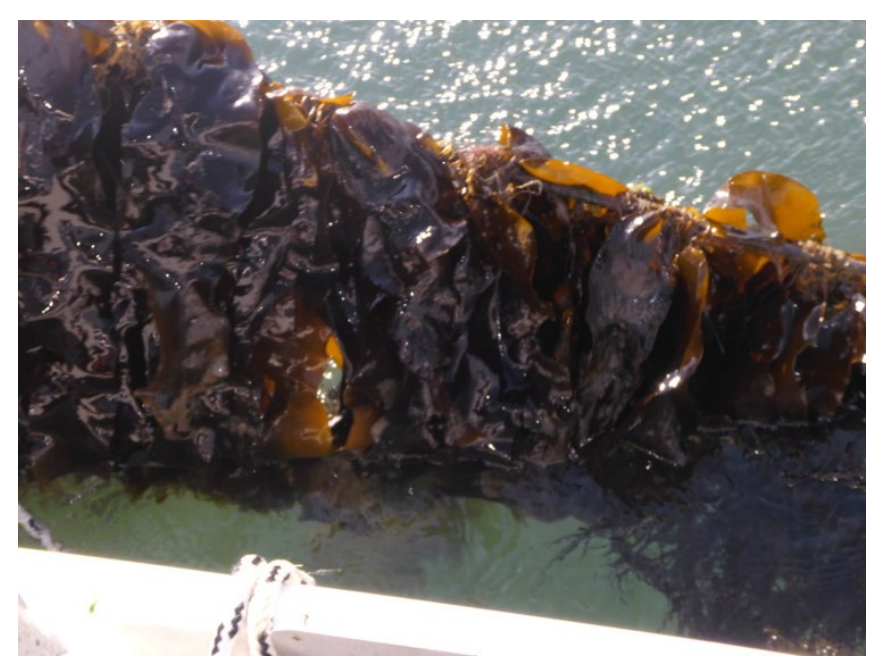

Figure 6 Photograph of the brown seaweed Saccharina latissima on cultivation ropes in the Schelphoek in July 2020.

\subsubsection{Analysis of video footage}

Analysis of video footage was conducted with VLC player (freeware; VideoLAN, École Centrale Paris, Paris, France). The footage of different cameras was compared and analysed for the time of first arrival (TFA), the maximum number of individuals present in the field of view at any time (MaxN), duration time of MaxN, and interaction with the bait. The filmed individuals were identified to the lowest taxonomic level possible. 


\section{Results}

\subsection{Early afternoon}

The baited camera system attracted fish within 10 minutes after its deployment at the seaweed site in the early afternoon. The first fish appearances in view were dominated by young horse mackerel (Trauchus trauchus) after 9 minutes and 38 seconds and continuously seemed intrigued by the bait, as their appearances continued for the whole observation time (Figure 7, Fig. 11).

However, there was not a lot of interaction with the bait bag directly and no active feeding was observed. A bad visibility caused by high turbidity in the water made it difficult to identify and quantify the numbers of fish present outside the baited camera system. Furthermore, fish were likely to circle around the bait coming closer slowly, which was difficult to follow on different camera views and therefore the presented numbers might be overestimated, respectively duration time of MaxN underestimated.

In addition, two types of jellyfish passed by the camera lenses during the recordings and were identified as compass jelly fish (Chrysaora hysocella) and blue jellyfish (Cyanea lamarckii) (Figure 8). Furthermore, a crab (unidentified) moving on the horizontal cultivation rope was recorded (Figure 9). 


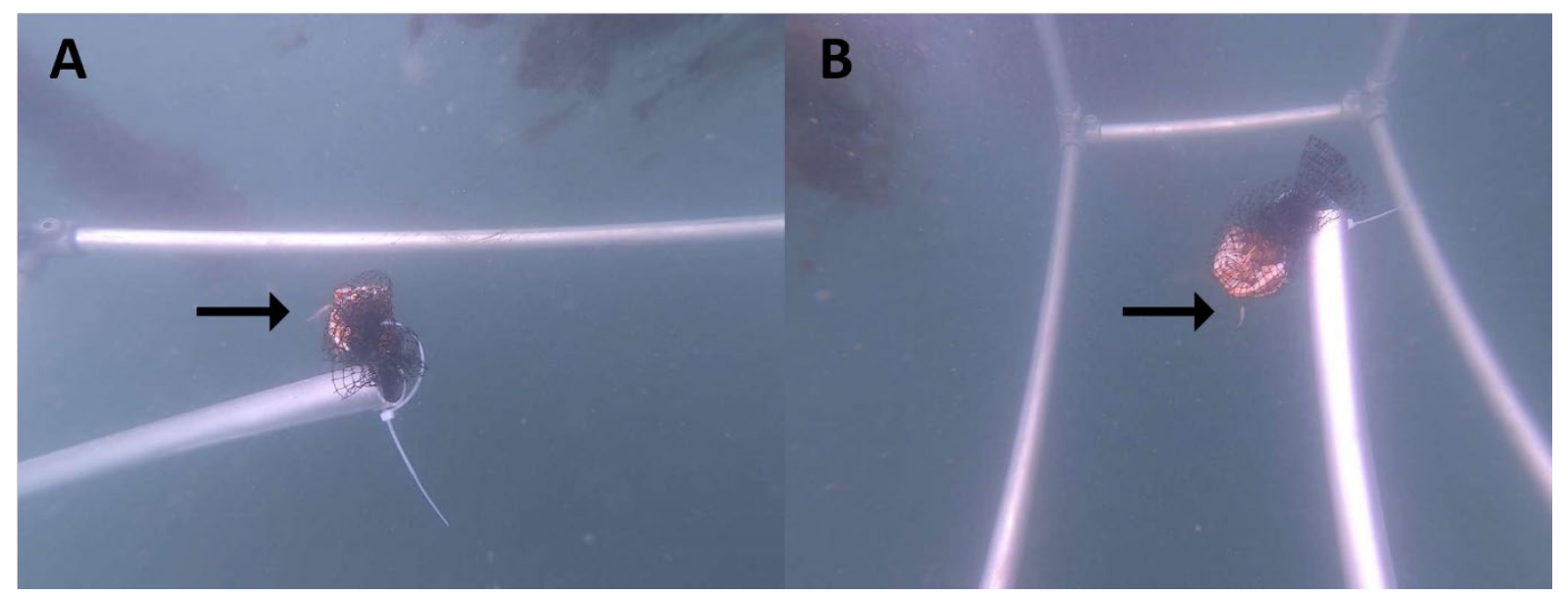

Figure 7 Typical fish appearances (A) single name and (B) multiple name in the view during recordings with a baited camera at a seaweed cultivation site in the Schelphoek in the early afternoon.
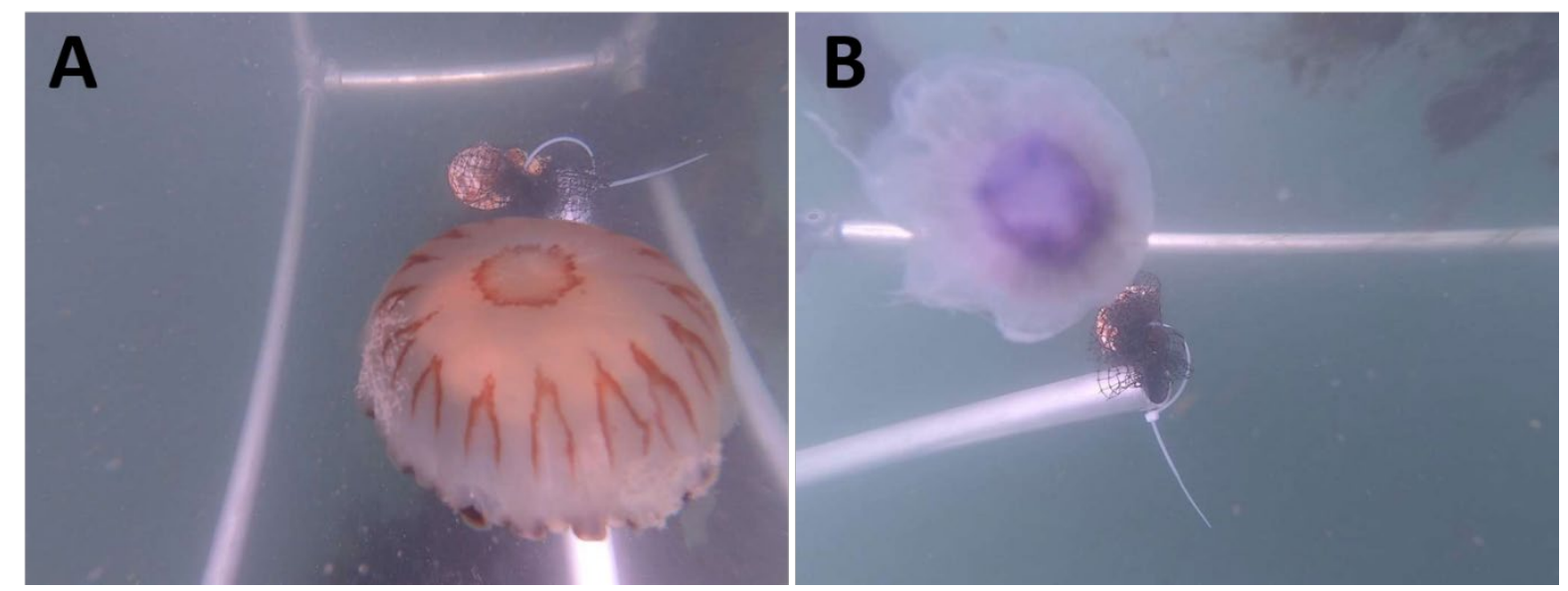

Figure 8 The jellyfish (A) compass jelly fish (Chrysaora hysocella) and (B) blue jellyfish (Cyanea lamarckii) passing by the camera lenses.

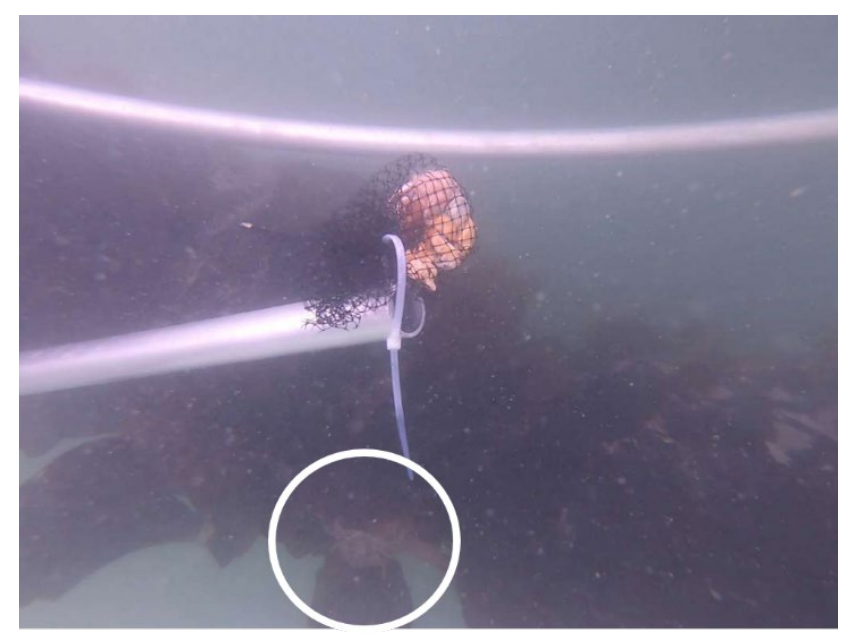

Figure 9 A crab (unidentified) crawling on a horizontally aligned seaweed cultivation rope. 


\subsection{Early evening}

During recordings in the early evening between $17 \mathrm{~h} 30$ and $18 \mathrm{~h} 30$ at the same position, one juvenile fish was observed feeding on the bait (Figure 10). No other mobile fauna, except for jellyfish hovering in the view were observed. The unidentified juvenile fish first came into view after 23 minutes, after deployment of the baited camera system, and immediately went to test the bait. The juvenile fish was interested in the bait and stayed in sight for approximately 1 minute, before leaving again (Fig. 11).

\subsection{Early afternoon vs. early evening}

There was a greater fish activity observable in the early afternoon hour, than in the early evening, when only one fish could be recorded (Figure 11).

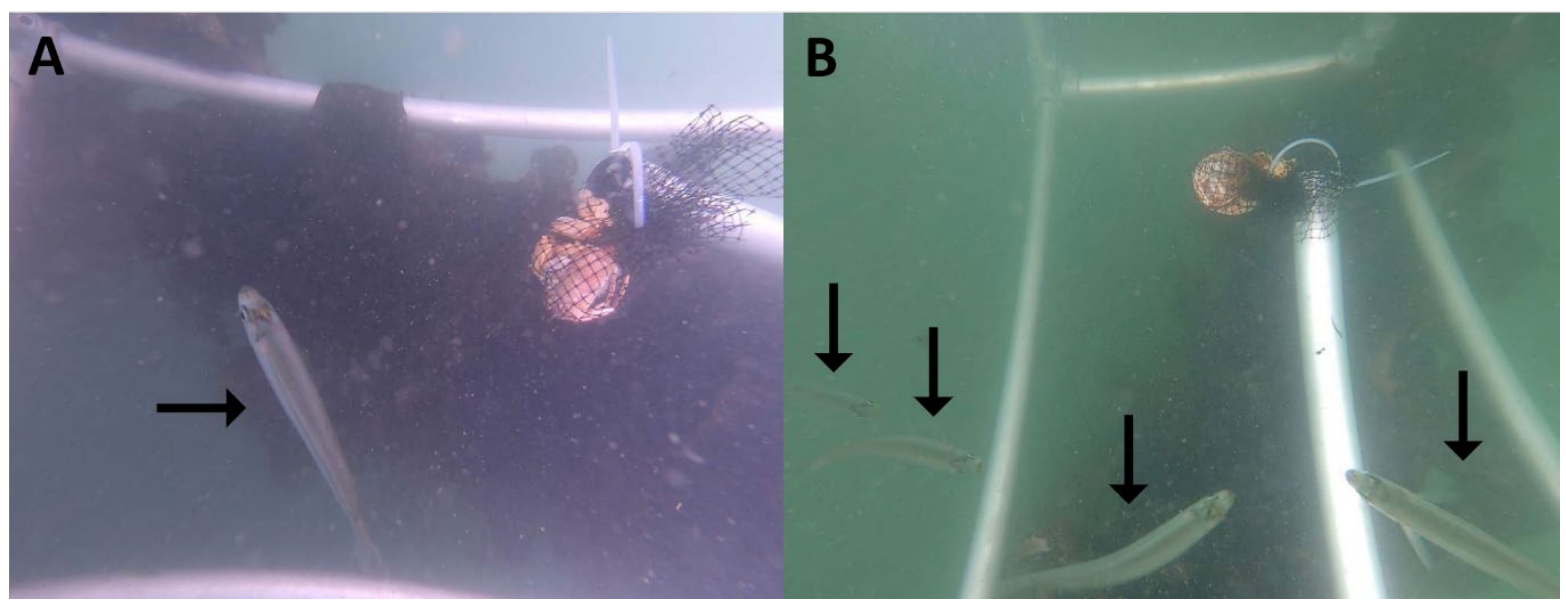

Figure 10 Unidentified juvenile fish feeding on the bait from different camera angles (A, B). 


\subsection{November 2018 vs July 2020}

In November 2018, the first results on video monitoring with a baited camera system at the seaweed test site in the Schelphoek were reported by Tonk et al. (2018). The monitoring by Tonk et al. (2018) took place at the same location (and depth) in the early afternoon, comparable to the time frame of the early afternoon recordings in this study. In November, the seaweed (S. latissima) on cultivation ropes had been deployed right before monitoring was conducted, hence cultivated biomass was very little compared to biomass in the beginning of July 2020 (note: deployed in November 2019). The results on fish monitoring in November 2018 showed a higher diversity in species composition and a MaxN that was twice as high as the MaxN of 7 observed in July 2020 recordings. An identical bait (mussel flesh, crab and shrimp meat) attracted fish already after 30 seconds after deployment of the system in November 2018, while fish appeared after approximately 10 minutes in July. The maximum numbers in fish were horse mackerel (Trauchus trauchus), a swarm fish, which is similar to results of MaxN in this study. Another fish species with a high abundance observed in the November 2018 recordings was the big scale sand smelt (Atherina boyeri), which could not be observed in the July recordings. However, in neither recordings of November 2018 and July 2020, it was possible to taxonomically identify all sighted fish species from the video material. Especially small fish $(1-2 \mathrm{~cm})$ are nearly impossible to taxonomically identify from the recordings. Small fish were sighted in the seaweed test farm in November 2018 after deployment of the cultivation ropes and also in July 2020, before potential harvest of biomass. Tonk et al. (2018) reported small groups of 4 to 8 individuals travelling alongside the horizontal cultivation ropes, while only one juvenile fish showed during early evening recordings in this study (Fig. 10, Fig. 11).

The assemblages of recorded jellyfish differed in November 2018 from observations in July 2020. In November 2018, the sea gooseberry (Pleurobrachia pileus) and the moon jelly fish (Aurelia aurita) were dominantly observed, while the compass jelly fish (Chrysaora hysocella) and the blue jellyfish (Cyanea lamarckii) were recorded in July 2020.

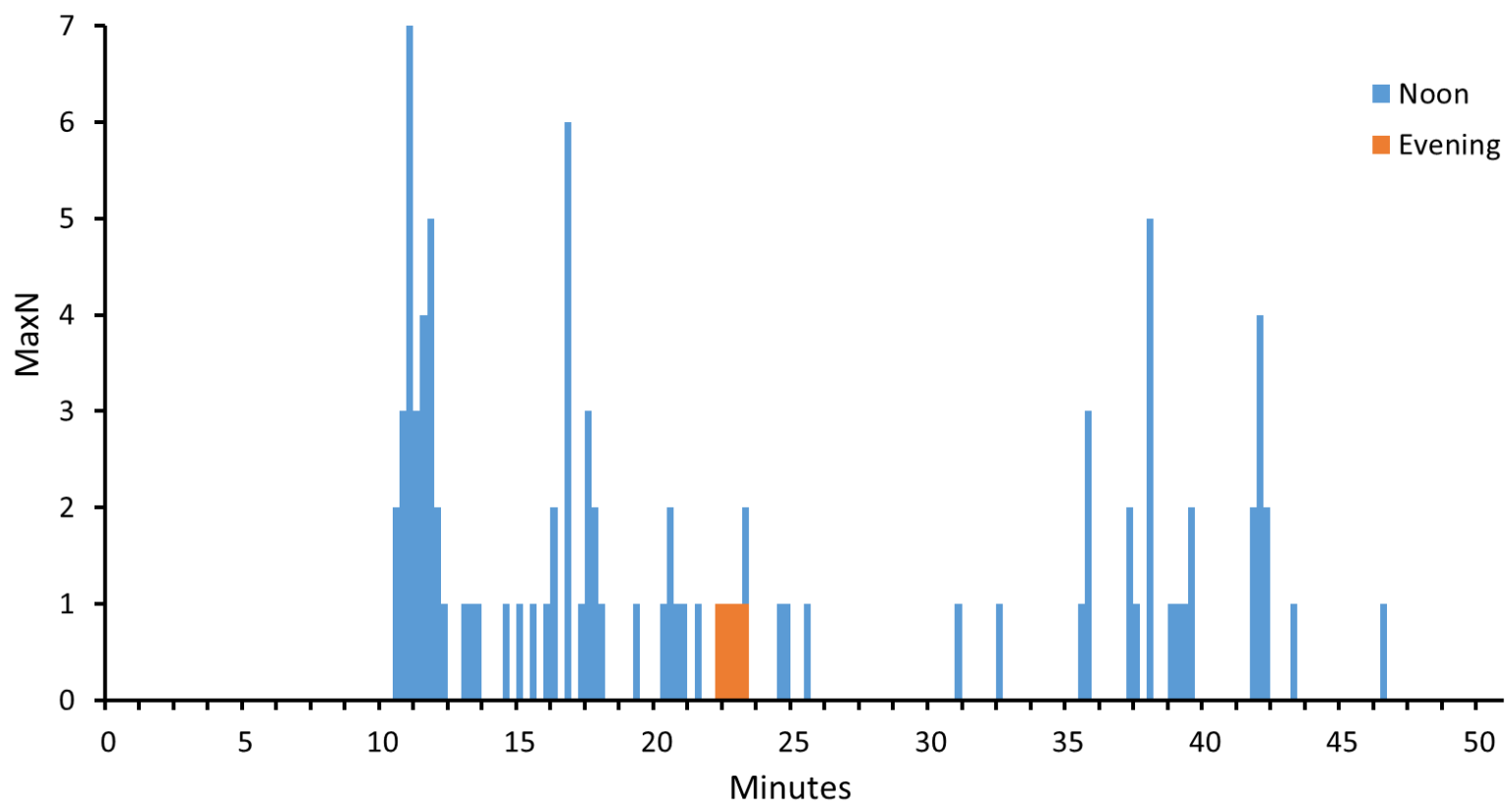

Figure 11 The maximum number of fish (MaxN) in camera view at any one time during a 15 seconds interval after deployment of the baited camera system during video observations at a seaweed test site in the Schelphoek around noon and early evening in July 2020. 


\section{Conclusions and recommendations}

\subsection{General conclusions}

The baited camera system has the potential to attract carnivorous and omnivorous fish, rather than herbivorous species (Cappo et al. 2007). However, the results of this study show that the time of deployment of a temporary monitoring system is crucial to observe underwater activity. In the early afternoon, there was significantly more fish activity, and interest in the baited system. Compared with the early evening hour, when there was only one juvenile specimen recorded. Seaweeds typically represent a nursery ground for pelagic fish, as well as offer shelter (Steneck et al. 2002). In correspondence to observations from Tonk et al. (2018), juvenile and small fish, respectively fish larvae occur near seaweed sites. This makes it difficult to taxonomically identify the species on video footage, but video monitoring represents the least intrusive method to gain information on underwater activities. Depending on the level of turbidity in the water and visibility, video monitoring may not only give information for identification and quantification of species, but also provides great pictures for presentations and public work. Observations from different camera angles improve the ability to identify species, as more information may be revealed from the footage (Figure 3).
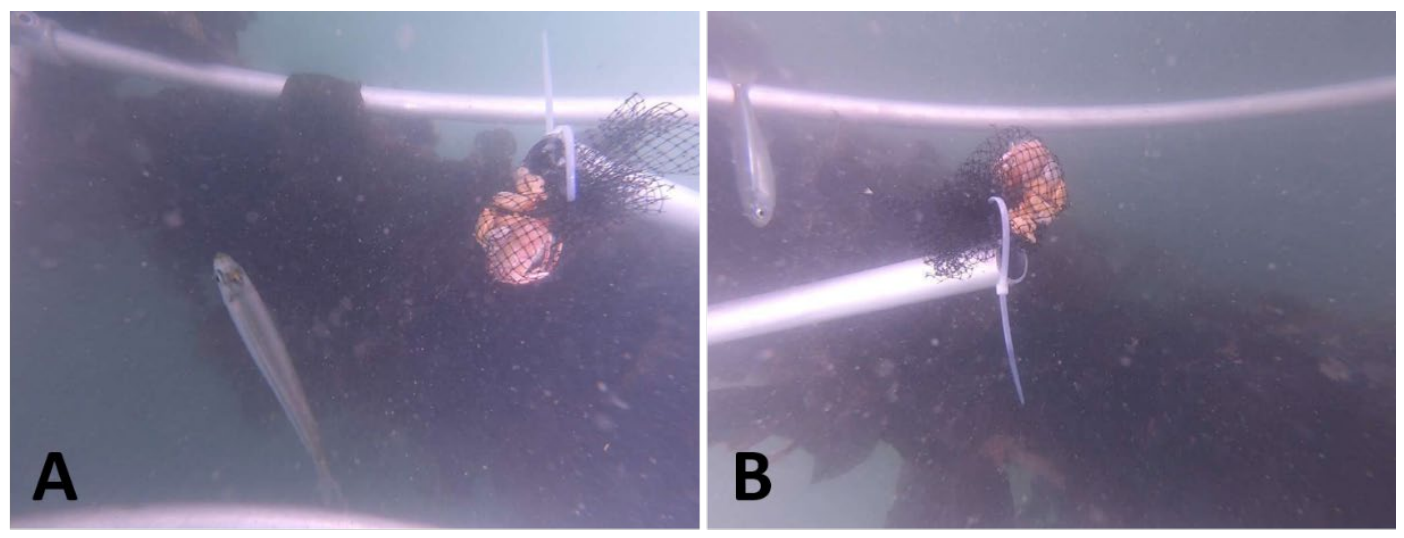

Figure 12 Video snapshots of (A) a mackerel (Trachurus trachurus) and (B) the same fish from a different camera positions. This arrangement allows for improvements in species identification of mobile fauna.

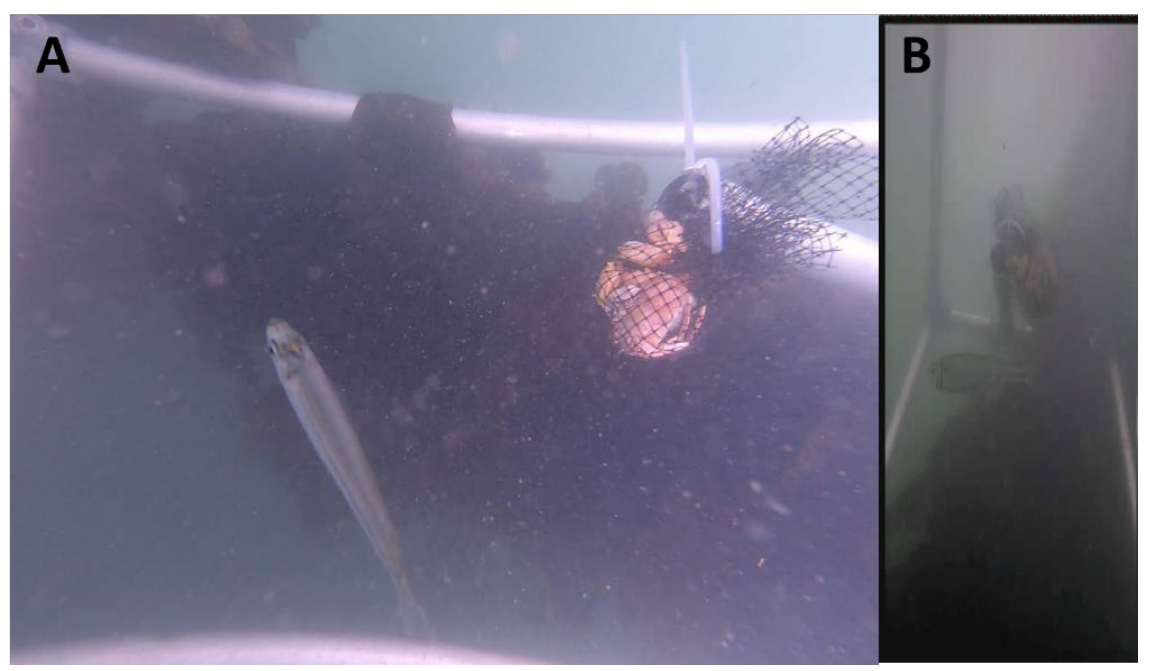

Figure 13 Video snapshot recorded by (A) action camera and (B) infrared camera. 


\subsection{Infrared cam vs. action cam}

Naturally, the images produced by an infrared camera are less brilliant, than comparable images produced by a digital action camera, due to their operation spectra (Figure 4). The resolution of the images of both types of cameras depend on their technical equipment. In this study, the infrared camera had a resolution of $800 \times 480$, while the action cameras recorded in $4 \mathrm{~K}$ resolution. A great advantage of the infrared camera was the live footage, which allowed to control the bait and optimize the position of the frame structure relative to the cultivation ropes. Furthermore, the infrared camera may be connected to an external energy source, if necessary, while the action cameras were able to record for about 60 minutes in regard to their 'battery life'. Adjustments to frame rates and resolution may extend the 'battery life'. A general disadvantage of the infrared camera was the cable connection from the underwater camera to the monitor on the boat, which prevented leaving the site and required a minimum of noise and movement.

The identification of fish was conducted from the footage recorded by the action cameras.

\subsection{Recommendations}

This study showed the importance of the daytime in regard to video monitoring. In future projects, monitoring should be considered to be conducted in the morning hours and during midday (as reference), as well, to assess daily fish activity and changes in 'visiting' fish assemblies near seaweed fields.

The baited camera system used in this study aimed to monitor carnivorous and omnivorous pelagic fish and their interaction with the bait. However, as seaweeds farms also affect the benthic life in terms of biomass input from detached seaweed fragments and reduced light levels, future studies should include an assessment of the benthic fauna, as well.

Furthermore, a combination of different kinds of bait are recommended for future studies. While this study used ensis and crab flesh, which typically attracts carnivorous and omnivorous fish species, corn and bread crumbs may be added to the bait bag to increase chances of attracting herbivore fish in close vicinity to the seaweed farm, too.

Biodiversity and composition is likely to change over the seasons. A frequent monitoring over a seaweed cultivation season (and beyond) should be conducted to get better knowledge on occurring and reoccurring fish assemblies and their interaction with the seaweed farm. A newly introduced seaweed farm site may attract an increasing number of species over time, in correspondence to its acquaintance to (migrating) fish. In long-term studies, this information may be compared to fish migration data from the North Sea area to assess potential consequences to (historical) fish migration patterns and routes. To provide a wider range of identification options, automated visual recognition should be considered for future development. 


\section{Quality Assurance}

Wageningen Marine Research utilises an ISO 9001:2015 certified quality management system. This certificate is valid until 15 December 2021. The organisation has been certified since 27 February 2001. The certification was issued by DNV GL. 


\section{Acknowledgement}

Our gratitude goes to Julia Wald, John van Leeuwent and other personnel from Seaweed Harvest Holland for permission, access, and assistance at their seaweed farm in the Schelphoek. Alexander Lubsch is responsible for the experimental design, performance and reporting. Romy Lansberg provided a secondary review on the report. 


\section{References}

Callaway, R., Alsvag, J., De Boois, I., Cotter, J., Ford, A., Hinz, H., Jennings, S., Kroncke, I., Lancaster, J., Piet, G., Prince, P. and Ehrich, S. 2002. Diversity and community structure of epibenthic invertebrates and fish in the North Sea. ICES Journal of Marine Science 59:1199-1214.

Cappo, M., De'ath, G. and Speare, P. 2007. Inter-reef vertebrate communities of the Great Barrier Reef Marine Park determined by baited remote underwater video stations. Marine Ecology Progress Series 350: 209-221.

Gmelig Meyling, A.W., Lente, I. van der, Schrieken, N., Gittenberger, A. and De Bruyne, R.H. 2013. Het Duiken Gebruiken 3: Gegevensanalyse van het Monitoringproject Onderwater Oever (MOO).

Hazard, T.P. and Eddy, R.E. 1951. Modification of the sexual cycle in brook trout (Salvelinus fontinalis) by control of light. Transactions of the American fisheries Society 80(1):158-162.

Lalli, C.M. and Parson, T.R. Biological oceanography - an introduction. 2. edition, publ. Elsevier, eds. Butterworth-Heinemann, Oxford, 1997.

McClelland, J.W. and Valiela, I. 1998. Changes in food web structure under the influence of increased anthropogenic nitrogen inputs to estuaries. Marine Ecology Progress Series 168:259-271.

Steneck, R.S., Graham, M.H., Bourque, B.J., Corbett, D., Erlandson, J.M., Estes, J.A. and Tegner, M.J. 2002. Kelp forest ecosystem: Biodiversity, stability, resilience and future. Environmental Conservation 29: 436-459.

Teal, L.R. 2011. The North Sea fish community: past, present and future. Background document for the 2011 National Nature Outlook. Wageningen, Wettelijke Onderzoekenstaken Natuur \& Milieu, WOtwerkdocument 256; pp. 64.

Tonk, L., Bernard, M. S., \& Jansen, H. M. 2019. The use of video-techniques for monitoring and quantification of mobile fauna in marine cultivation systems. (Wageningen Marine Research report; No. C017/19). Wageningen Marine Research. https://doi.org/10.18174/471068. 


\section{Justification}

Report C111/20

Project Number: 4318300156

The scientific quality of this report has been peer reviewed by a colleague scientist and a member of the Management Team of Wageningen Marine Research

Approved: $\quad$ M. Poelman MSc

Researcher Aquaculture

Signature:

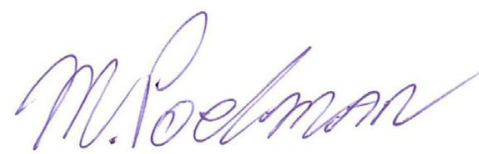

Date:

$19^{\text {th }}$ of January 2021

Approved:

Drs. J. Asjes

Manager Integration

Signature:

Date:

19th of January 2021 
Wageningen Marine Research

T +31(0)317480900

E: marine-research@wur.nl

www.wur.eu/marine-research

Visitors' address

- Ankerpark 271781 AG Den Helder

- Korringaweg 7, 4401 NT Yerseke

- Haringkade 1, 1976 CP IJmuiden
With knowledge, independent scientific research and advice, Wageningen Marine Research substantially contributes to more sustainable and more careful management, use and protection of natural riches in marine, coastal and freshwater areas.

Wageningen Marine Research is part of Wageningen University \& Research. Wageningen University \& Research is the collaboration between Wageningen University and the Wageningen Research Foundation and its mission is: 'To explore the potential for improving the quality of life' 